\title{
Los pueblos indios y la sociedad mayor; niveles de integración y formas de dominio
}

\section{Jesús Ruvalcaba Mercado}

Centıo de Investigaciones y Estudios Supenores en Antropologıa Social Cuudad del Mexico Mexico ruvalca@cresas edu mx

\section{Serg1o Eduardo Carrera Quezada}

Universidad Nacional Autonoma de Mexıco Ciudad del Mexıco Mexıco ıztlacyo@hotmail com 


\section{Resumen}

En las siguientes lineas se habla acerca de las relaciones mas comunes establecidas a lo largo de la historia entre los grupos indıos y la sociedad mayor Se parte de que las mismas nunca han sido de caracter reciproco sino ventajosas para esta ultima y por lo mismo en detrimento de los primeros Este es uno entre los multıples temas de los que se ha ocupado el profesor Sílvıo Coelho dos Santos a lo largo de su fructifera vida Aqui solo abordaremos las relaciones de caracter violento las de integracion y las de intercambio desigual de trabajo y mercancias cuando no del despojo vil de territorio y recursos naturales indıgenas con ejemplos de Mexico y Brasil Se notara que las mas frecuentes implican crimenes de Estado y que tienden a la expoliacion de las comunidades indigenas por parte de la sociedad mayor Al mismo tıempo los pueblos indios sobreviven por un sin fin de estrategias no meras respuestas sino busquedas confrontaciones o acoplamientos adecuados a lo que la sociedad mayor les trata de imponer

Palabras claves pueblos indios mecanismos de dominacion formas de intercambio
Abstract

This article focuses on the most common relationships formed inroughout the history between Indians and the larger soctety Never having had a rectprocal character they have been advantageous for the latter and accordingly detrimental to the indigenous societnes This is one theme among many to which Professor Silvio Coelho dos Santos dedicated his productive life Here we will examine only those relations of a violent character those of integration and unequal exchange by means of commercial goods and wage labor that have accompanied the plunder of their territory and natural resources Using examples from Mexico and Brazil it is observed that the most fiequent of these actions imply crimes of the State and that they further the explottation of the indigenous communitzes on the part of the larger society At the same time the indigenous communities survive by innumerable strategies that are not mere ractions but explorations be they confrontations or adequate reconciliations to what the surrounding society tries to impose

Keywords indigenous peoples strategies of dominance exchange relations 


\section{Introducción}

Tos problemas que aquejan a las poblaciones indıgenas en MéxıLco y Brasıl o en general en toda América, se deben en parte al rezago historico en atender sus demandas, en contextos donde la explotacion económica la opresion social y la represión armada han prevalecido como las formas de relacion entre aquellas y la sociedad dominante, problemas cuyo origen se remonta a los perıodos colonial e independiente y que, al mismo tıempo, se han agravado o ampliado, afectando a las sociedades rurales de todo el mundo y de América en partıcular En definıtıva, los pueblos indıos no han sido integrados al reparto de la riqueza, pese a que, paradójıcamente, gran parte de esta se genera en su seno, sea por la explotacion de sus recursos o por la utılızación de su esfuerzo

Otro factor en la historia de los pueblos indios es su situacion geopolitica, que los ha hecho partıcipar en el pasado y en el presente en una situación de dominacion por parte de la sociedad mayor, proceso en el que se involucra la riqueza de sus recursos naturales como los hidricos, el petroleo, el gas natural, los minerales las riquezas forestales, la producción agrícola, el trabajo artesanal y la venta de fuerza de trabajo Como lo anterior se ha hecho en nombre del progreso nacional, en beneficio de la nación y sin tomar en cuenta la opınıon de los pueblos indigenas, los mismos han quedado marginados de los beneficios derıvados En consecuencia, la pobreza y la marginacion, cuando no el exterminı, se presentan como las principales consecuencıas de la accion de las naciones en su relacion con la poblacion indıa Otros aspectos como el fenómeno mugratorıo, la sobreexplotación de los recursos naturales y los problemas derıvados de la violencia en su 
contıa sólo podrán resolverse cuando se busque la partıcıpacion real de los pueblos indıos en los proyectos de desarrollo correspondientes, con informacion suficiente, y cuando se les haga partícipes en la toma de decisiones (Santos, 2003 91)

Ya el sustantıvo "ındıo" aplıcado a los pueblos orıgınarıos de Amérıca, además del extravıo geográfıco, nos revela el fracaso de la cultura europea del siglo XVI por entender la enorme variedad y naturaleza de las formas de vida, actıvıdades económucas y relacıones especificas de los pueblos americanos encontrados en las primeras expediciones de conquista Con todo y su diversıdad, al quedar dominados por la sociedad que los engloba en limitadas posibilıdades, la naturaleza de cada etnia condiciono en buena medıda el futuro de los grupos indígenas mediante diversas formas de relación (Santos, 1992 31) Las más comunes fueron y son todavia el extermınıo, la confınación en reservas territoriales, las misiones y su incorporacion mas o menos forzada a la vida nacional, sobre todo por medio de la educacion y como mano de obra en los niveles mas bajos de la escala laboral $\mathrm{S}$. sólo fuera por lo que la sociedad mayor les umponc, es probable que los pueblos indıos habrian ya desaparecido Hasta ahora, estas formas de relacion han sido estudiadas pero no siempre del todo comprendidas en térmınos académicos y, ya en la practıca, en ningun pais de Amerıca se les ha permitıdo a los pueblos orıgınarıos ser dueños de su propıo destino En el mejor de los casos, se los conserva porque funcionan como una frontera inteina para la expansıon del mercado y también como reserva de mano de obra para el sector industrial A pesar de esta visıón un tanto fatalısta y desalentadora, cabe señalar que se han alcanzado grandes avances en beneficio de la poblacion indıgena a nivel continental e internacional, principalmente en el ambito de los derechos colectivos, ambientales y cultuiales no se puede dejar de consıderar que la adquisıcıón de derechos y reconocimientos jurídıcos tambien es parte de estas formas de relacion

Estos "niveles de integracion" (Santos, 1987 19), sin contar el exterminıo llano, se han diseñado sıempre desde la sociedad mayor en detrimento de los pueblos originarios (Santos, 1975 11-12) Al respecto es importante remarcar que las formas de incorporación de los pueblos indios a la sociedad nacional no siguen una secuencia 
histórica smo que, dado su caracter funcional, se pueden presentar de manera indistinta, a veces aparejadas entrc sí Tampoco guardan relación con el numero de indígenas, como lo prueba el hecho de que mientras en la Huasteca mexicana existen alrededor de 1000000 de individuos pertenecientes a alguno de los grupos etnicos, en el sur de Brasil la población indígena suma alrededor de 35000 (Santos, 1994 168) Es decir se equivocan quienes piensan que a la conquista armada, una vez pacıficados, le sıguıo la evangelızación seráfıca, la peı suasıón apostolıca o la integración cultural, pues cuando la socıedad mayor, nacional o regional, requiere de los recursos o de la fuerza de trabajo de los pueblos indígenas aplica la fuerza, el cohecho, la persecucion, la incorporación o el exterminıo desde los primeros contactos hasta nuestros dias, incluso en el grado de "el genocidıo y el etnocidıo" (Santos 1994 166) Estas formas de dommı que la sociedad mayor ejerce sobre los pueblos indıos se debe a la necesidad del sistema mas amplio de expandırse o mantenerse principalmente, por medıo de la expoliación de los recursos naturales, por la explotación de la mano de obra o por la transferencia de valor en los procesos de compra venta de las mercancias que se producen en uno y otro sector Para analizar estas circunstancias, aquı solo se usaran dos ejemplos contrastantes en cuanto a la naturaleza de los grupos aunque sumular en cuanto a los resultados la colonización y el dominio de los pueblos indıos de la Huasteca, Méxıco, y las relaciones de los grupos guaraníes con la sociedad nacional y con el Estado en el sur de Brasıl

\section{Los pueblos indios y su domunación}

Una de las principales caracteristicas de la Huasteca desde antes de la conquista europea es su diversıdad etnica y ecologica La Huasteca presenta tres ambitos muy marcados y duferentes la planicie costera, el pıe de montaña y la sıerra Cada nıcho ecológıco se distıngue por la ocupacion del suelo (producción agnicola para la subsistencia, cría y engorde de ganado, plantaciones comerciales de frutales), el grupo que predomna (mestızos o indigenas), la lógıca de produccion (principalmente para la comercializacion o para el auto consumo), y otras cuestiones como las vias de comunicación existentes, el tamaño de los asentamıentos urbanos los servicios públicos, la flora y la fauna etcetera 
Los grupos que la pueblan no sólo pertenecian y pertenecen a diferente filıación linguística, sino que también diferían sobremanera en cuanto a sus actıvidades económicas Antes de la Conquista habia grupos recolectores cazadores y otros sedentarios, con un alto grado de urbanısmo, sistemas agncolas complejos y sometıdos a las exacciones y tributacion por parte de un Estado Por las fuentes del siglo XVI es muy dıfícll, sı no imposible, saber cuantas personas habitaban la Huasteca en la epoca prehıspanica Pero según el cálculo de Juan Manuel Pérez Zevallos, habia un poco más de un mullon de personas, sin que se pueda decir cuántos eran nauas, huastecos o teenek, otomíes, totonacos, pames, etcétera En el ultımo cuarto del siglo XVI -de acuerdo con el mapa de Ortelius- habıa un poco más de 150 pueblos con nombre teenek (unico grupo huasteco de la familia protomaya) en una gran region al norte del no Panuco, en las cuencas de los ríos Tamesi y Guayalejo, cuyos limites eran hacia el norte hasta el río Las Palmas, actualmente Soto la Marına, y por el poniente la Sierra de Tanchipa Dada la fecha de ese mapa, 1584, hay que considerar que ya había habıdo movluzaciones de pueblos completos motivadas por los abusos ejercidos por conquistadores y colonizadores hıspanos, como se desprende de la Visita de Gómez Nıeto a 44 pueblos de la regıon en 1532-33 (Perez Zevallos, 2001) Estudios arqueologicos suponen que la ocupación teenek iba desde el norte del actual Tamaulupas (Stresser-Pean, 1977 478) hasta El Tajín (Wulkerson, 1980 216), testumonios que debemos tomar con ciertas reservas pues las evidencias no distınguen entre los teenek propiamente y los demás grupos con los que estos convivían

Por su parte, el sur de Brasil se caracterizo por contar con una poblacıón indıgena trashumante y sedentarı (lo mismo que en la Huasteca) perteneciente a los grupos guaraní, kaingang, xokleng y xetá, mientras que se colonizo con inmigrantes de las Islas Azores y luego los venidos de España, Portugal, Alemanıa, Italıa y, en menor medıda, de Polonıa, Ucranıa, Austria, Sina, Grecia, Japón y poblacion judía Es decir, de manera diferente, también se trata de una region multiétnica (Santos, 2007 27-28), aunque de forma inversa, pues mientras en el sur de Brasil la mayor variedad esta dada por los migrantes europeos, en la Huasteca es mayor la varıedad de grupos indıos que la de los mestızos 
Respecto al grupo guaranı, las investıgaciones arqueologicas, historicas, linguísticas y etnológıcas han demostrado que el territoroo ocupado por ellos antes del período colonıal se extendia por los actuales estados merıdıonales de Brasıl, el orıente de Paraguay y el noreste de Argentina y Uruguay, conocido como el delta del Río de la Plata (Noellı 2004 17-18) La región sur del actual Brasıl había sido poblada por cazadores recolectores unos 12000 años a C Alrededor de 2500 años atras llegaron grupos del tronco lınguistıco Macro-Jê, provenientes del centro-oeste, y después se asentaron grupos de fulıacıón lınguístıca Tupí (es decır, los guaranıes), quienes arrıbaron de la región amazónica (Noellı, 1999-2000 228) Los 3000 sitıos arqueológıcos atribuidos a los guaranies demuestran una ocupacion en el sur de por lo menos 2000 a C Santos (2007 39) apunta que en Santa Catarina su presencia data del 1000 a $C$

Los asentamientos guaraníes precoloniales se situaban en cuencas hidrográficas, con un manejo agı oforestal que les permitia la obtencion de recursos para su subsistencia Los conjuntos de aldeas (tekoas) conformaban amplios territorios, denominados con el termino de guarás, donde se mantenıa un manejo agrıcola de rozas itınerantes (Noellı, 1993 247, 260) Por medıo de ambos, los tekoa y los guaras, los guaranies mantuvieron el control de este territorıo frente a otros grupos linguisticos, principalmente los Jê, a traves de un sistema de curculacion, tanto de personas como de bienes intercambio de semillas y de relaciones de parentesco, y también mediante la guerra Este modelo de territorıo guaraní se vio afectado por el proceso de conquista y colonızación europea a partır del sıglo XVI, que fiagmento los antıguos guarás y desestructuró a los tekoas

Ahora el territorio mbya-guaraní es caracterızado por ser una construcción simbólica y geográfica en la que se ejerce un domınıo mediante la realızacion de practicas culturales y su constante reproducción, de forma que los espacios que la conforman deben posibilıtar una exıstencia en la medıda de lo posıble lo mas apegada al "modo de ser guarani", es decur, "perfecta", inspirada en los preceptos religiosos, los cuales tienen una correspondencia durecta con espacios ecologicos adecuados y medios ambientes preservados 
La aldea guaraní, o sea el tekoa, no se refiere nada mas al local de residencia o al espacio usufructuado por el grupo, sino que posibilita la reproduccion cultural de todos sus miembros, tanto individual como colectiva, de tal modo que el espacio para fundar una aldea debe ofrecer las condiciones necesailas para reproducir y transmitır este "modo de ser colectivo" (Melıa, 1986, Ladeira, 1989 336, Litaiff, 1996 49) Se trata de un modelo ideahzado de lo que debena ser una aldea guaraní pues a la fecha y a causa del intenso contacto interetnico, la dificultad para encontrar espacios con dichas caractensticas ha creado controversıas en torno de como debe ser una aldea Tambien las práctıcas culturales de los guaraníes experimentan transformaciones cada vez más aceleradas debido a sus relaciones con la sociedad nacional lo que pone en tela de juicio el concepto de "modo de ser guarani", su perfeccion y su presunta pureza

\section{Extermunio o integración}

Entre las principales secuelas que produjo la Conquista en la Huasteca hay que mencionar los efectos devastadores de la venta de esclavos a Las Antıllas que tanto Cortés como Nuño de Guzman impusıeron en la regıon, con la justıfıcacıón de que allı no se encontraban metales preciosos y por ello no habia otra forma de atraer o arraigar a los pobladores españoles (Chıpman, 196789 o 2007 65) Las razzıas por las que decenas de miles de esclavos (se mencionan desde 12000 hasta alrededor de 40000 ) se transportaron de forma llegal a las lslas del Carıbe provocaron el despoblamıento de comunıdades enteras, la emıgracion a zonas lejanas del dominıo español y la recomposıción de sus relaciones con otros grupos indigenas

Lo anterior no difiere de lo que aconteció en el sur de Brasil El pı ımer contacto entre guaranies y europeos en el sur de Brasıl se dıo precısamente en el litoral catarınense en São Francisco do Sul LoS primeros contactos no fueron hostules, aunque enseguida dıo inıcıo la violencia en contra de la población natıva (Perrone-Moıses, 199622 , Santos, 2004 39-53, 2007 38) La vasta poblacion de los guaraníes o caryo que ocupaban las costas del sur de Brasil (alrededor de 100 mil individuos) fue diezmada "debido a la violencia y a la voluntad explicita de los [europeos] recien llegados por someter a los indigenas" 
(2007 41) Como en el resto de America fueron practicas comunes el rapto, el abuso sexual de las mujeres, la apropiacion de los bienes de los indigenas la esclavitud de los indıos para someterlos al trabajo forzado ademas de las enfermedades que los blancos trasmitieron a los pueblos indios de America Las contınuas expediciones de los conquistadores españoles evidencian que durante el proceso de conquista el litoral catarınense era de importancia geopolitica para los europeos, pues el puerto de la Lagoa dos Patos era uno de los principales puntos logísticos de los españoles para tener acceso al Mar del Plata por la via maritima y a la ciudad de Asuncion por el interior del territorio (Darella, 2004129 131) Además, las alıanzas politicas y matrimoniales que efectuaron algunos españoles con ciertas hyjas de los lıderes guaraníes les permitıó a los europeos avanzar hacıa el interıor de las sierras y llevar contıngentes de indıos como guias y como guerreros para combatir a otros grupos hostlles (Noell, 200421 )

El proceso de conquista, caracterizado por la esclavitud, las epıdemias, las guenas regionales y la deforestacion, obligo a que grupos guaranies abandonaran sus aldeas y emprendieran una dispersion forzada desde las costas hacia zonas de dificil acceso en direccion al oeste Aqui habria que distinguir entre dos grandes grupos de guaraníes El primero era el de guaranies reducidos y controlados por los españoles dentro de las encomıendas (Susnık, 1965, I 161 164) El segundo fue un contingente de guaraníes denommado ka ygua o "monteses ', que resistían someterse al trabajo en las encomiendas y al control de los españoles (Melıá, Grunberg y Grunberg, 1976 169) De cualquier modo, la ocupacion española del territono sureño durante el sıglo XVI sıgnuficó el inicıo de la pérdıda del territorıo guaranı Sin embargo, el periodo mas largo e intenso de dicho proceso fue entre los siglos XVII y XIX, con la llegada de nuevos contungentes de inmıgrantes europeos La presıón ejercıda por la socıedad mayor, las actıvıdades agropecuarıas, la extracción compulsıva y la desmesurada deforestacion intensificados durante los sıglos de colonızación dejo a los guaraníes ka ygua sın posıbılıdades de refugıarse más en las selvas y se vieron obligados a exponerse, ya que el contacto con los blancos sería inevitable Por su lado, en los territorios ocupados 
por famılıas de la etnıa xokleng, los encuentros eran generalmente violentos en exceso (Santos, 1987)

Surgió así, por parte de la sociedad dominante, la pregunta de qué hacer con estos grupos de "salvajes", con el fin de proteger sus industrias y tambien de apropiarse de los espacios habitados por los indıgenas En aquel momento surgıeron dos posıbılıdades inmedıatas La primera fue el extermınıo, que era ejercido por los propıos colonos y que llego a ser incluso una forma de trabajo y un sistema de vida La segunda fue la integración paulatına pero forzosa mediante el control de entudades gubernamentales creadas para dicho fin, las afamadas instituciones indigenistas En el caso de Mexico fue el Instituto Nacional Indigenista, y recientemente su desestructuracion en la Comision Nacional para el Desarrollo de los Pueblos Indigenas Su homologa en Brasil fue el Servicio de Proteccion al Indio y después la Fundacion Nacional del Indıo (FUNAI) Huelga decir que estas instituciones gubernamentales, lejos de atender las demandas y mejorar la situación de pobreza, discrimınación y exclusıón de los grupos indigenas dentro de los correspondientes territorios nacionales, emanan una serie de metodos para ejercer poder y control desde el aparato estatal sobre las poblaciones indigenas

\section{Despojo de tierras}

Al termmar las guerras de conquista se inició la usurpacion europea de las tierras indígenas En la Huasteca, Huejutla y Tantoyuca encomenderos y conventos agustmos ocuparon tierras que convirtieron en haciendas para la cria de esclavos, caballos, mulas y reses La expansión de las haciendas alcanzo su maxımo en los sıglos siguientes de manera que solo en los tres paitidos del antıguo distrite de Tancanhuitz (Tancanhuitz, Tamazunchale y Valles), que coincide con la Huasteca potosina, se contabılızaban cası una treintena de hacıendas, la mayor parte de ellas no menores a las 10000 hectareas (Santos Santos, 1991 2a parte) No se necesita de gran estudio ni intuicion para saber que todas ellas pertenecian a los pueblos que habitaban allı es decır, a los abuelos y antepasados de los nahuas, teenek pames, otomies, totonacas, etcétera Para dar idea de la magnitud del despojo, solo hay que decır que en térmınos de lo que hoy es el oriente de San Luis Potosí 
Los pueblos indios y la sociedad mayor niveles de integracion y formas de dommio

se conformaron dos grandes haciendas entre otras muchas la de San Juan Evangelısta del Mezquite y anexas, que hacia 1643 comprendía alrededor de 450000 hectárcas (para crecer hasta cerca de las 700000 ) y San Ignacıo del Buey, que alcanzó una extensıon de 600000 hectáreas y se consolido en el siglo XVII (Agullar-Robledo, 1998127 128) Su posterior division, la aparicion de otras propiedades menores $y$ sus transformaciones durante la colonia y la independencia pueden consultaise en ese artıculo

Durante el siglo XVI sc unicio el pioceso de introducción y expansıon de la caña de azúcar, platano y citrıcos que habrian de tener una rapida y gran acogida por parte de todos los grupos indios de la Huasteca Tanto en la planicie costera como en los lomerios al pie de la sierra, la caña de azúcal, los cerdos y los platanos se untrodujeron cası ıecién termunada la conquista Fue tan exitosa su produccion y aceptación por parte de la población indígena que hacia 1580 cası todos los pueblos indios de la region producían, consumían y comercralızaban la caña de azucar y sus derivados (principalmente piloncillo y aguardıente), tenıan plátanos que consumían y vendıan en los tıangus regıonales $\mathrm{v}$ criaban piaras de puercos cuya manteca llevaban a vender a los mercados de las grandes cuudades como Puebla, Mexico y Pachuca Por su parte, los españoles que se habran asentado en la regıón criaban ganado mayor, sobre todo para el aprovechamiento de sus cueros y sebo, que mandaban a España o a los centros mineros umportantes Pero en lo que se diferenciaban de los ganaderos del Altuplano, en numero de animales y en calıdad de los mismos, fue en la cria de mulas a que se dedicaron los ganaderos hispanos de la Huasteca Esta fue una actıvidad realizada tanto por manos privadas como por las órdenes relıgıosas parrocos y curas de la region En los pueblos de la costa del Golfo se contunuaba con la pesca, cuyos productos se llevaban a vender tanto a los pueblos de la sierra como a veces a sitios mas lejanos en el Altıplano central

Por su lado, el refugio de las selvas permitio hasta hace algun tıempo que los guaraníes establecieran contactos esporádıcos con la sociedad nacional, fue el agotamiento de los recursos lo que oblıgó a la sociedad dominante a echar mano sobre estos espacios Los guara- 
níes no tuvieron más remedio que establecer contacto intenso con la sociedad nacional y aprovecharse de las estructuras occidentales para demandar el derecho sobie sus tierras y los recursos contenidos en ellas El proceso en que los guarames ocupaban tradıcionalmente los espacios para la fundación de sus aldeas puede ser unterpretado a partir de dos ejes El primero es el descubrimiento y la eleccion de espacios adecuados que cumplan con las condiciones ecologicas suficientes para la reproduccion del grupo, a traves de una revelacion divina El segundo sigue las referencias basicas y las antıguas ocupaciones, o sea, la reocupacion de los espacios previamente identıficados por los líderes relıgıosos (y tambien polítıcos) guaraní En este sentıdo, la ocupación es un sistema ciclico (Garlet, 199782 83) En ambos cjes, el proceso es dirıgıdo por un líder tradicıonal, sea un jefe de famulıa extensa que conduce a su grupo al nuevo espacio, sea un líder religioso de mayor prestıgıo que dirige un conglomerado de grupos de parentesco, o bien, un cacique o lider político que "consıguio una tıerra" La argumentacion de estas ocupaciones está basada en la orientacıon chamánıca medıante la experıencia onírıca, interpretada por los guaraníes como revelaciones de los lugares dispuestos por Nhanderu, la principal deldad guaraní (Mello, 2001 42)

Lo que muestra el siglo XX y lo que va del XXI es un proceso de recomposicion etnica y territorial guaraní Poco a poco, el terntorio que antes de la ocupación española estuvo ocupado por los guaranıes, ha sido parcialmente recuperado No solo eso, smo que ha sido ampliado -si se lo concibe como un territorio discontinuo como muestra la formacion de aldeas y su desdoblamento a lo largo del siglo XX y comienzos del presente (Garlet, 1997 49) En la actualıdad, los gua raníes configuran su territorıo a través de la interrelacion del conjunto de áreas ocupadas, dispersas a lo largo del litoral sureste y sur del país, desde Espiritu Santo hasta Rio Grande do Sul, y en los estados de Mato Grosso y Mato Grosso do Sul, extendiendose al norte de Argentına y Uruguay como tambien gran parte de Paraguay y Bolivia

El estado de Santa Catarina experımenta este proceso nuevo de ocupacion de su territorio de forma acelerada, lo que es una manifes tacion de visibilidad de los guaraníes frente a la sociedad nacional 
Los pueblos undıos y la sociedad mayor nuveles de integracion y formas de dominıo

La formacion de aldcas y campamentos se situa, en general, en areas de dominı público -como en las orillas de las carreteras y en otros casos ocupa propiedades partıculares cedidas o invadıdas, sin contar las que se encuentran dentro de tierras indígenas demarcadas para otros grupos étnicos como los xokleng o kaigang Las situaciones jurıdıcas en la mayoría de estas aldeas guaraníes son irregulares, debido a un atraso institucional por parte de la FUNAI El proceso de reocupacion responde tanto a las necesidades de reproducción fisıca y cultural de los guaranies en la búsqueda de espacios de vegetacion preservada, como a un derecho de reivindicacion del espacio tradicıonal A lo largo de la historia, los guaraníes han mantenıdo una estrecha relacion con el paısaje bıoclımátıco denominado Mata Atlantıca regıon que se extıende a lo largo del litoral sur de Brasil, que es una de las areas con mayor bıodıversıdad en el pais, asocıada a su cosmologıa, organızacion socıal, polıtıca y económıca (Ladeira, 1996)

\section{La economía y la producción}

Las actividades económicas más sıgnificatıvas de los grupos indios huastecos sedentarios en el siglo XVI eran la agricultura (maíz, frijol, chile camote, frutales diversos y hortalizas) el comercio (chile, hachuelas de cobre, frutales, cuentas para collares, objetos suntuarıos de plumas preciosas y pelo de conejo) y la produccion y transformacion del algodón (en greña, mantas de diversos tıpos, huipıles y naguas) La agricultura se practicaba bajo el sistema de roza, tumba y quema con tres -o al menos dos que hasta ahora persisten- momentos de siembra anuales en la misma parcela, y tambien habia sistemas mas intensivos como algunos camellones tipo chinampa cerca de la costa o de terrazas hacia la sierra Asımısmo cultivaban y transformaban el algodón y producian cacao y vainulla, aunque estos dos en pocas cantidades Producian ademas miel esteras de palma y tule, canastos, cestos de bejuco, cordeles, bolsas y morrales de zapupe, peces, marıscos, frutas tropicales, productos elaborados de cera y tal parece que sal, obtenıda tanto del mar, esteros ros y lagunas, y también cal, que fabricaban de la concha de una almeja Estas mercancias entraban a los circuitos comerciales a través de los tıanguis regıonales o por medio de las encomiendas En sentıdo inverso, a las comunidades indıas 
se les obligaba a comprar mulas, telas o incluso objetos suntuarios como medias de seda traídas del lejano orıente Sı bien la producción y tasación del tributo era individual, la produccion para pagarlo era colectıva y el cabıldo indígena asumía o se le imponıa la iesponsabılldad grupal para pagarlo Gran parte de los pueblos mesoamencanos, incluidos desde luego los que sobrevivieron en la Huasteca, deben a esa organızacıón colectıva de gobıerno su supervivencia

Ahora, las mercancias que se compran y venden han cambiado, excepto las que conforman los alımentos basicos Lo que permanece como constante es que mentras las que producen los campesinos indigenas se compran muy por debajo de su costo de produccion, las que ellos compran del sector industrial a veces triplican el precio, lo mismo quc los servicios Por ejemplo, si una artesanía cualquiera cuesta cunco unıdades para el público general, el productor solo recibıra una, y las otras cuatro quedaran en manos de los intermediarios Por otro lado, cualquier servicio que en la cludad tenga un costo de una unıdad, en las zonas indígenas costará tres Desde luego, no es tan simple el fun cionamiento de estas cadenas, ya que los altıbajos tienen que ver con las cosechas, la epoca del año, el tıpo de intermedıarıs, la exıstencıa doméstica de reservas, entre otros factores El interesado encontrara una explicacion mas detallada en Ruvalcaba Mercado (2002)

Similar al sistema agrícola de los indios huastecos, los guaraníes realızan la siembra de maı, tuberculos y legumınosas mediante el sistema de roza, tumba y quema Hasta hace algunas décadas y mientras permanecieron refugıados en las selvas y con poco contacto con la sociedad dominante, la base de la subsistencia de las familıas guaranıes era la agricultura, la pesca, la caza y la recolección actıvidades que difícılmente ahora se pueden realızar debıdo a la falta de espacıos adecuados para la agnicultuı y la escasez de especies para la cacería la pesca o la recoleccion Si bien anteiormente la base economica guaranı era de subsistencia y consumo dentro de lo que cada unidad doméstıca producia, cazaba o recolectaba, en la actualıdad la econo mía depende, en su mayoría, de la venta de las artesanuas y de lo que medianamente pueda obtenerse a partır de donacıones, además de los miserables programas asıstencialıstas generados por las instıtuciones 
gubernamentales Realmente son pocas las mercancías producidas por las familias guaranıes que entren en los curcuitos del mercado, con excepcion de las artesanias, pero la mano de obra, proporcionada principalmente por los jovenes, es de lo que mas se ha favorecido la sociedad nacional, sin contar con los recursos naturales que se extraen de su terrıtorıo Mas bien, podria ubicarse a la población guaraní como consumidora de los productos industriales generados poi la sociedad dominante pues una vez aniquilada su base economica sustentada en el auto consumo, esta se presenta como una potencial dependiente de los bienes producidos por las industrias

\section{Formas de gobierno}

Acerca de la forma de gobierno que permanece en los pueblos indios de tradicion mesoamericana, todo parece indicar que es el resultado de instituciones que existían antes de la conquista pero que a la vez se mezclaron con otras traidas por los españoles, sobre todo por la ıglesia y, dentro de ella, por los fraules agustinos y franciscanos, como las cofradias y las hermandades religıosas Como no es aqui el espacio para profunduzar acerca de su funcionamento, hay que decur al menos dos cuestiones al respecto La primera es que estas instituciones fueron de suma importancia tanto para la vida colonial de los pueblos indios como para diversas cuestiones de la vida comunitaria actual la consecucion y la defensa de su territorio, la composicion y funciones de las autoridades comunales que forman su sistema de gobierno, sus cargos y las mayordomías religiosas existentes No obstante, esta afırmacion debe ser matızada puesto que muchas comunıdades que hoy son exitosas se fundaron en el siglo XIX y nunca tuvieron cofradias, aunque las hayan conocido en su comunidad madre La segunda cuestıón al respecto es que exıste una amplıa bıblıografıa que analıza en profundidad el sistema de cargos y textos recientes que modifican su entendimiento (para la Huasteca se pueden consultar los textos de Carrera Quezada, 2008, Cruz Peralta, en prensa e Iciek, en prensa)

Junto con sus bondades, el sistema de cargos tambien presenta debilidades y fallas Una de las que recién se ha resaltado es que a los cargos mas altos llega menos del diez por ciento de los pobladores, mientras que las obligaciones y cargos menores recaen en la mayoría 
Incluso se afırma que ese camıno cada vez mas estrecho explica en buena medıda la conversıon relıgıosa que se ha incrementado en las ultumas decadas Diversos investıgadores coincıden en señalar que la conversıón a las sectas protestantes responde en gran medıda a que el tradicional sistema mesoamericano de cargos da cabıda sólo a un grupo selecto de los miembros de la comunıdad Nada más unos cuantos partıcıpaban o partıcıpan en los cargos de mayor jerarquia, mientras que la mayoria aportaba trabajo o recursos, antes para el pago del tributo y el pago de las fiestas religiosas y, ahora, para el cuidado de las instituciones o de los bienes comunales como las escuelas, la iglesia, los hatos colectivos el reparo o la reapertura de los linderos, la produccion de la parcela colectiva y, desde luego, todavía, para el pago de las fiestas patronales Muy pocos son los que pueden llegar a ejercer los cargos de mayor responsabılıdad como juez, representante de bienes comunales mayordomo de la ıglesıa, etcetera Según esa ınterpretación la conversıón a otras relıgıones les ofrece a los margunados -los que primero se convierten- la posibılıdad de emprender un camıno duferente hacia el liderazgo y el prestigıo Asimismo, la conversión religiosa junto con el hecho de guardar ciertos preceptos, como la prohıbición de ingerır alcohol, repercuten en una mejora cası ınmedıata de la calıdad de vida de la unıdad domestıca que encabeza ese determinado jefe de famılıa Dicha mejora resulta, además, notorıa para el resto de la comunidad

Lo anterior se ha explicado como un aporte más a la propuesta de Max Weber, puesto que sı en las comunidades indias los conversos al protestantismo muestran mas inıciatıva y una rapıda mejoría material tan pronto dejan la religión catolica, entonces Weber tenıa razon al asociar cierto espintu del protestantismo con la aparıcion y el desanollo del capıtalısmo En efecto, esta asociación puede explıcar en parte por qué crecen las relıgıones no catolıcas en las comunıdades aunque no esclarece el asunto de la transformacion unıcıal nı el panorama relıgıoso, que sin duda es más complejo En un estudıo reciente (Quiroz Uría 2008) se da cuenta de un movimıento relıgıoso entı mesıánıco y tradicional, que encabezo una mujer nahua a quien la investıgadora describe como una joven con gran liderazgo carısmatico 
Los pueblos indıos y la sociedad mayor niveles de integracion y formas de dommı

Movimientos religıosos carısmátıcos ha habıdo muchos en Mexıco y en Brasil, lo mismo que en otras zonas indias y campesınas mestızas de America Estos movimientos fueron estudiados por medio de los actores y junto con una serie de condicıones y circunstancias diversas de caracter social, agrarıo, politico y religıoso, en el marco de un ambiente caracterizado por la discriminacion, la represión y la explotación de los mestızos hacia los pueblos indıos La autora de esos estudios concluye que, con frecuencia, estos cambios religiosos responden justamente a las condiciones en que se mantıene a los pueblos indıos del país Es decir, se trata más de una búsqueda de cómo palıar la explotación economica y la discriminacion de que son objeto los pueblos indios que de una busqueda de riqueza material individual o familiar Las mujeres se cuentan, en este sentıdo, entre las mas actıvas

Por su parte, los guaranies tambien ejercen practicas de poder y mantienen estructuras politicas internas, menos institucionalizadas qut en el caso mexicano pero igualmente visıbles y efectivas en cuanto estructuras que permiten una cierta resistencia frente a la presion de la sociedad dominante La familia extensa es la referencia básıca de la unıdad económica, polítıca y relıgıosa de los guaraníes, y esta es dirıgıda por una pareja de líderes religıosos y polıticos que conducen a su grupo en busca de nuevos espacios y la fundacion de nuevas aldeas, por lo que la familia tambien es un grupo de migracion (Cicarrone, 2001, Pissolato, 2006, Gaulet, 1997 123) En este sentıdo el proceso de reocupación territorial guaranı no se efectúa de manera aleatoria, sino que obedece a logicas y estrategias propıas de su sistema sociopolitico Por un lado, corresponden a la busqueda de espacios adecuados para la fundacion de un tekoa, pero también responden a las relaciones polítıcas internas del grupo, que no per miten la coexistencia de dos lideres politicos o religiosos en la misma aldea, lo cual orıgina la cısıón de los grupos de parentesco y tambien la formacion de nuevas aldeas (Chase Sardı, 1992 200)

\section{Los mecanismos de integración}

Ya que se habla de la expoliación, la opresıón social y la vıolencıa, hay que mencionar, aunque aqui no se las trate en extenso, que las tres contınúan siendo problematicas graves en la America indıgena, 
tanto en Mexico como entre los grupos estudiados por el profesor Sílvio Coelho dos Santos En dos artículos previos, uno de los autores analızo cómo se utılızan esos mecanısmos en la Huasteca, a veces a la par, a veces de manera secuencial (Ruvalcaba Mercado, 2002) y sus semejanzas con lo quc pasa en el Brasıl (Ruvalcaba Mercado, 2004) En la Huasteca la opresıon ya no está relacionada exclusivamente con la cuestıon agrarıa, pero sin duda esta cuestıón, la de la tenencia de la tierra, sigue como un problema candente y vigente al que no se le ha dado una solución satısfactorıa Sin duda, porque el papel que juega el sistema de cargos para mantener el funcionamiento y la cohesion de la comunıdad es fundamental Al analızar, juzgar y sancionar casos y no situaciones generales, las autondades comuntarias logran un mayor poder de negociacion y consenso, aunque sea a costa de la eficiencia administrativa, la democracia comunitaria y en ultumo termmo, de las garantías indivıduales Es decir, en la medıda en que las autorıdades realmente representan a los untereses colecuvos y demuestran su efı cacia, el sistema de cargos se constituye en un contrapeso de las tres plagas sociales mencionadas y dısmunuye sus efectos más negativos

\section{La migración}

Hace varios meses, en mayo de 2007, durante una visita que hicieron los alfabetizadores a la zona pame oxı ol como ellos se nombran (que, dicho sea de paso, es el grupo indígena con menor numero de hablantes en la Huasteca apenas unas tres decenas de famulias en Queretaro y unas 800 en San Luis Potosı, es decir, alrededor de 6000 en total), uno de los jovenes de la comunıdad, cası adolescente, expresó con toda conviccion que en lugar de una educacion bilmgue en castellano y $x \imath$ or era mejor que se les enseñara ingles, porque el como todos los de su generación, hombres y mujeres, no tardarıan en migrar a los Estados Unıdos Cuando se recorren los caseríos de Las Nuevas Flores, El Pocito y San Antonıo Tancoyol, que son los lugares que ellos habitan en la Sierra Gorda queretana, o Santa María y Santa Catarma en San Luis Potosí, uno podria suponer que el joven tiene toda la razon puesto que se trata de tierras pedregosas con escasez de agua y cası ningún habitante tiene derecho a una parcela propia Sin embargo, se sabe que allı exısten canteras de pıedras para la construcción, que

\section{ILHA}



ahora están en manos de los mestızos de la cabecera, lo mismo que las tıerras con mejores posibilidades agropecuarıas Por otro lado, en las comunidades nahuas de Hidalgo, Veracruz y San Luis Potosí, que es el grupo indígena mayoritarıo con cası 300000 hablantes en la Huasteca, con tierras propıas cası todos ellos y con comunidades consolıdadas o al menos que les ofrecen mejores oportunidades a su juventud, pasa algo semejante la migracion de los jovenes de ambos sexos en busca de trabajo alcanza cası el 40 por ciento de la poblacion

La migracion entre los guaraníes se presenta de forma diferenciada, puesto que esta practica es inherente a su sistema sociopolítico y relıgıoso La migracion no se enmarca únıcamente en la busqueda de fuentes de empleo o mejores condiciones laborales, sino en encontrar espacios adecuados que les permitan reproducir su sistema cultural en el cumplimiento de sus prescripciones relıgıosas Ciertamente, las condiciones de misena que experimentan las aldeas guaraníes oblıga a que muchos de sus miembros, e incluso familias enteras, se desplacen hacia otras aldeas para hacer mas pasadera su vida cotıdiana, pero colocando como principal fundamento la necesıdad de una mejorıa espiritual, mas que material

\section{La infraestructura}

Aunque los servicios básicos de agua, electricidad, drenaje y co municacion todavia son insuficientes, se han incrementado de manera notoria en los ultımos cuncuenta años Las carreteras fueron trazadas con criterıos para facilitar la extraccion de maderas finas en el siglo XIX y luego, en el XX, para la explotacion del petroleo en la zona costera, territorio que por su riqueza se llego a conocer como La Faja de Oro Hoy se encuentran varias nuevas carreteras que se adentran en la sierra y cruzan donde habita la mayoria de la población indígena Según se afırma, ello tıene tambıen como objetıvo abrur el acceso al ejército por sı hubiera algún problema con la explotacion del gas natural que se extrae de manera incupiente del Paleocanal de Chicontepec Es decir, para controlar a la poblacion, ya que todo ese complejo forma parte del Plan Puebla Panama

Tanto en el Golfo de Mexico como en el sur de Brasil la apertura de vías de comunicacion tambien ha servido para que mas personas 
salgan de su comunudad, y con mucha mayor frecuencia, a trabajar, estudiar, pasear o visitar a sus familiares Esta claro que este es un fenómeno que mantıene grados de dıferencıa según del grupo etnıco del que se trate, ya que el transporte puede ser utılızado como un recurso para satısfacer ciertas necesidades especificas, tanto materıales, emocionales y tambien espirituales En el caso de los indigenas huastecos, cuya economia esta inserta en el sistema capitalista nacional, el transporte es utlluzado para sacar con mayor rapidez sus productos y trasladarse ellos mismos por la region para vender sus mercancias u ofrecer sus servicios, pues, con el dinero de los migrantes, varias familias han logrado hacerse de una o dos camıonetas para transportar a sus coterraneos a cambio de una cuota que todavia para muchos resulta onerosa $S_{1}$ ponemos atención en estos aspectos, una característica actual de las comunidades indıas en Mexico (o en la Huasteca sı ası se prefiere) es que se ha incrementado la dıferencıacıón socıal No parece acertado hablar de clases al interior de las comunıdades indias, pero una observación mínıma da cuenta de la diferenciacıon notorıa entre las famılıas

Por su parte, para los guaranies del sur de Brasıl, la apertura de camınos y otras obras de infraestructura representa una paradoja Por un lado, la construccion de carreteras pioduce un impacto ecologico, social y economico directo en las aldeas indígenas, y por otro, un mayor acceso a las vias de transporte ha contribuido al fortalecumiento de las redes de parentesco, a la economía basada en la reciprocidad y el intercambıo de bienes, característıcas básıcas de la organızación sociopolutıca guaraní En ambos casos, Mexico y el sur de Brasıl, se aprecia que el uso de las vías de comunicacion por parte de los grupos étnıcos tıene como fundamento comun el mejoramiento de la calıdad de vida

\section{Los recursos naturales}

El recurso que ahora esta en juego es, en la Huasteca, la explotacion y extracción de una reserva de gas, contenıda en el Paleocanal de Chicontepec Como es sabido y relacionado con lo anterior, es decir la explotacion economica o expoliacion de los recursos naturales, la opresion social cuya manifestación mas evidente $\epsilon$ la discriminacion, y la represıón por parte de los cuerpos armados del Estado (polıcias, 
paramilitares y mulitares), la Huasteca fue una zona de importancia mundial en la produccion de petróleo desde finales del siglo XIX hasta el ultımo tercio del sıglo XX No obstante la extracción de esa ınmensa rıqueza no dejó benefıcıo alguno a las comunıdades, excepto algunos caminos y empleos que de cualquer manera se localızan fuera de lo que fue La Faja de Oro A pesar de la gran riqueza extraida, no hubo creacion de empleos, fuentes de trabajo o inversion en la in fraestructura que propiciaran el desarrollo permanente de la region Los beneficıarıos locales de dicho proceso fueron algunos mestızos a quienes se les rentó o compro la tierra mientras duraba la explotacion, mientras que los pueblos undıos quedaron al margen de la curculacion de la riqueza, aunque a algunos pocos se los integro en los trabajos peor remunerados Los nos de riqueza que circulaba en la manos de los tecnicos extranjeros, en contraste con la pobreza de los indıos de la region, han sido motıvo de novelas películas, libros artículos y do cumentos oficiales del gobierno mexicano y en todos ellos queda de manifiesto el control ejercido sobre los habitantes y propietarios de las tıerras por parte de las compañias petroleras extranjeras, al prıncıpıo, y luego por la propia compañıa de Petroleos Mexıcanos (PEMEX) por medıo de la violencia, el cohecho, las amenazas o las compras obligadas, el disımulo o la desaparıción de los renuentes Asimısmo, queda de manifiesto el deterioro del medio ambiente y la desaparicion de cientos o miles de especies que poblaban la regıón Con el trabajo de campo actual y los propıos datos oficiales, lo que resulta evidente es la pobreza, el abandono y la marginación de los mismos pueblos que fueron los dueños de esa riqueza descomunal

El Paleocanal de Chicontepec Este yacımıento está formado por un inmenso manto de gas natural que con la tecnologia y los precios contemporaneos se ha convertido en una fuente enorme de riqueza Se trata de un manto petrolero de unos 3100 hulometros cuadrados, ya en explotacion por compañías extranjeras, donde viven nahuas, totonacos, otomies, tepehuas y mestızos, en el que se estımaba "incorporar en el año 2006 una producción de $39 \mathrm{mil}$ barrles por dia de petroleo crudo y 50 millones de pies cúbicos de gas por día" segun anuncio el durector de PEMEX, en julıo de 2003 (http //www enfoqueveracruz com/analısis/ 
paleocanal_2 htm) El manto se extıende en la sierra de Chicontepec por los municipios del mismo nombre, Benuto Juárez, Chilılıco y varıos otros con numerosas comunidades indígenas Segun la intencion oficial, la población local se vería beneficiada en 15 años con una inversión inicial de $310 \mathrm{mul}$ millones de pesos y 5000 empleos temporales

cQue les va a dejar a los pueblos indios que se asientan en la superficie del mismo? Por lo pronto, algunas carreteras que al mismo tiempo faciltan la represion en caso necesario, la incertidumbre de sl les acarreará contaminación y de que tipo y en caso de que se organicen en un nivel supra comunitarıo, algunas concesıones de gasolıneras más algunas instalaciones comunitarias escuelas, clinicas, restauracion de edificios publicos y no mucho mas Una evaluacion actual undica que las comunidades indigenas no se han visto beneficiadas en absoluto por la riqueza extraída y que de no tener una organızacion regional les sucederá algo parecido a lo que sucedıo con la explotación petrolera de La Faja de Oro cuya riqueza se fue a otıos sectores de la sociedad y a las comunidades les dejó el deterioro de su ambiente y la extuncion de numerosas especies anmales y vegetales Se puede decir que fue una transformacion "De 'paraiso' a 'tierra baldıa", en menos de 15 años (Santiago, 2002 321-347) Considerando que se trata entonces del futuro de estas otras comunudades que se veran afectadas por la explotacion del Paleocanal y con la ocupación del terreno, es necesarıo tomar en cuenta tambien la histonia agraria de la region y la legislacion acerca de la explotación de los recursos naturales (Diaz Garcia, 2007)

Entretanto, desde la decada de 1990 en el estado de Santa Ca tarina los gobiernos federal y estatal han intensificado la realizacion de proyectos de desarrollo con efectos de impacto global sobre áreas ocupadas por poblacion guaranı, localızadas principalmente a lo largo del litoral del estado La construcción del gasoducto BoliviaBiasil la duplicación de la carretera BR 101 y, en un futuro proximo, la construccion de una línea de transmision electrica financiada por la Electrosul, son proyectos que afectan de forma durecta a las aldeas Mbyá-Guaranı asentadas en el htoral catarınense Como resultado de los efectos causados por la realizacion de estas obras, los líderes de las aldeas guaranies junto con diversos agentes que los apoyan (antropólogos, grupos religıosos ONG ambientalıstas sectores izquierdıstas 
del gobierno, entre otros), ejercen una presion social y politica sobre el gobierno federal y las empresas contratistas con el objetıvo de garantızar el reconocimiento del derecho de la poblacion guaraní a las tierras que tradicionalmente ha ocupado

Un ejemplo de esto se dio en 1999 cuando las aldeas guaraní consiguieron la indemnización por la construcción del gasoducto Bolıva-Brasıl, recurso que fue destınado para la compra de un area, llamada Tekoa Marangatu, en el munıcıpıo de Imaruı, hacıa el sur del estado (Litaiff et al, 1999) La adquisıción de esta area resulto paradıgmatica, tanto para los líderes guaraníes como para los funcıonarıos del gobierno federal y las empresas constructoras A raíz de la duplicacion de la carreta BR 101, la expectatıva era la indemnizacion de las aldeas para comprar más áreas, sin desocupar las existentes De tal forma, este proceso de indemnización por parte del gobierno federal poco a poco ha sustıtuido los procesos constıtucionales de demarcación y homologación de tıerras indigenas en el estado de Santa Catarına

La primera aldea guaranı de la que se tıene regıstro etnográfıco contemporaneo en Santa Catarına es Tekoa Yma, mejor conocida como Morro dos Cavalos, en el munıcıpıo de Palhoça (Bott, 1975, Santos, 1976) El local fue identıficado por Rosa Marıa Bott en 1975, y al año sıguıente Sílvıo Coelho dos Santos describıó las condıcıones de la aldea la cual se componía de trece miembros - es decır, una únıca familia extensa - y sus medios de subsistencia eran la venta de artesanías, una pequeña parcela de plantación de maíz y batatas y la prostıtucion de las hijas Santos remarca el violento contacto interetnico con los blancos, ası como el desinteres de la FUNAI y otros órganos del gobierno en asıstir al grupo (1976 69)

La construccion de la carretera BR 101 en la decada de 1960, y después la creación del Parque Estatal de la Sierra del Tabulerro en 1975, fueron proyectos que afectaron de manera sıgnificatıva a la aldea de Morro dos Cavalos, pues ambas redujeron el espacıo orıgınal del área Ademas, el contacto interétnıco se intensifico en detrimento de la población guaraní A causa de estos proyectos de desarrollo se realızaron las primeras investıgaciones sıstematıcas que demuestran que Tekoa Yma tiene por lo menos 70 años de ocupacion contınua la cual no simplemente se explica por las condiciones ambientales 
en correspondencia con el sistema de subsistencia cultural guaranı, sino por el hecho de representar un espacio estratégıco que artıcula las redes migratorias y las relaciones de reciprocidad entre las aldeas (Ladeura, 1991, 2002, Lutauff et al, 1999, Darella, Garlet y Assis, 2000) Esta aldea es el espacio a partur del cual salıeron núcleos familıares para establecer nuevas aldeas y campamentos a lo largo de la costa meridıonal y septentrional catarinense, entre las que se destacan $M b t$ guaçu Massiambu Cambirela Praıa de Fora Terra Fraca y Tekoa Marangatu (Mello, 2001 26) El caso de la formacion de las aldeas de Massiambu y Tekoa Marangatu muestra muy bien que el proceso de reocupación guaraní se lleva a cabo y tiene una correspondencia con los procesos sociopoliticos del grupo Al mismo tiempo, muestra que el proceso de adquisicion de areas ha sido interpretado y se le ha dado un nuevo significado por parte del grupo etnico

La compra de tieira surge como una medida palıatıva para es quivar los procesos constitucionales y tambien para amortiguar las relaciones de conflicto entre propietarios privados y la poblacion guaranı que ocupa sus terrenos, reclamados como territorio tradicional, y por lo tanto sujetos a la homologación y expropiacion por la via constitucional Sin duda, el centro de las disputas es el control y la disposición sobre los recursos naturales que se encuentran dentro de las tierras undigenas La pretension de los gobıernos federal y estatal era que, mediante la compra de tierras para los indios la reubicacion de la poblacion de las aldeas dentro de nuevas areas permituría la liberacion de espacios para ser destmados a obras de infraestructura o inversiones unmobiliarias Pero la realidad muestra lo contrano la expectativa de adquirır nuevas tierras ha producıdo que se establezcan nuevos asentamentos en areas privadas y publicas, lo cual ha orıginado nuevas relaciones de conflicto con los propietarios y con los órganos de gobıerno, quienes se ven comprometıdos y presıonados por la población guaranı para garantızarles un espacıo

\section{Palabras funales}

En la actualıdad, las comunidades indígenas son territorıos de donde se pueden obtener recursos naturales estrategicos para beneficio de la sociedad mayor, como el petroleo en la Huasteca o la constiuccion 
de las enormes obras de infraestructura en el Brasul En los casos en que la economia indigena depende en su mayoría de la sociedad nacıonal, los territorıos undigenas han llegado a ser reservas de mano de obra para el sector industrial, consumidores de productos industriales, fabricantes de numerosos valores de cambio, productores de alımentos basicos resguardo y cobijo de los y las trabajadoras que deshecha la industria, el comercio o el sector de la construccion, seguro de vida para enfermos y accidentados y espacio de crianza de los infantes, costos todos que debieran ser pagados por los sectores empleadores pero que por la desatencion social se les cargan a las comunidades Pero, por otro lado aquellos grupos étnicos cuya economıa esta basada en el auto consumo y la redistribucion de los recursos han logrado articular su forma de vida con el sistema de la sociedad dominante, efectuando diversas estrategias de adaptacion y apropıacion de lo que ellos consideran favorable para mantener su cultura

En la Huasteca han aparecido varlas ocupaciones para quienes cuentan con algunos recursos, ya sean generados por las propias personas o bien provenientes de las remesas que les llegan desde el exterior Estas son las que tienen que ver con el transporte regional, con el comercio en las plazas semanales de la region y, aunque muy limitadas, con nuevas ocupaciones como tocar en grupos musicales o formar parte de las cooperativas de produccion y consumo que tambien exısten Los empleos defınıtıvos o plazas que se contratarán para la explotacion del manto de gas natural serán para gentes de afuera o herederos de plazas petroleras Pol su parte, los trabajadores de las comunidades seguran con la migracion hacia las empresas agricolas del centro norte y noreste del pais (Durango, La Laguna, Sinaloa, Sonora y Baja Calıfornıa) y, en el caso de los más arriesgados, hacıa los Estados Unidos Por su lado, las mujeres segurran con sus viajes en busca de empleo a las cuudades importantes como Guadalajara Monterrey y el Distrito Federal o a las de la frontera como Matamoros, para trabajar en el servicio doméstico, en el comercio informal o en las empresas maquiladoras

Por otro lado, al partir de la contradiccion entre los modelos ıdealızados y la realıdad, se percıbe la necesıdad de crear discursos que explıquen para sı mismos y también hacıa la sociedad nacional, 
el por qué de las transformaciones en sus sıstemas culturales En este sentıdo, se debe ponderar que la causa princıpal de estas transforma ciones y adaptaciones culturales se debe a la cada vez más intensa intervencion de la sociedad dominante, de la irrupcion de los no undigenas en la vida social de los que sí lo son, lo que los ha obligado a crear estrategıas de adecuacion y re elaboración cultural para fundamentar su permanencia Los nuevos significados otorgados a los elementos de la cultura occidental y a los efectos que estos tienen en su propia cultura no son unicamente explicaciones sino mecanismos de defensa cıeados a raiz del encuentro de dos practıcas distuntas de poder polítıco (Wolf, 2003 338)

Entre los guaranies, las transformaciones de ciertos aspectos culturales aparecen junto con una explicación del grupo y toman un nuevo significado El consumo de productos industrializados en complementarıedad o sustıtucion de las practıcas agricolas, la fabricación de artesanıas para su comercıalızación dentro de las relacıones de mercado en las grandes ciudades el creciente consumo de medicamentos alópatas y las consultas médıcas en las agencias de salud oficıales -en contraste con la cada vez menos frecuente participacion en rituales terapéutıcos realızados por los especialıstas relıgıosos-, la movilıdad de individuos entre las aldeas motıvada por la realızación de fiestas y campeonatos de futbol, la elaboracion de CDs con músıca y cantos relıgıosos la construcción de casas con materıales "no tradıcıonales" son ejemplos del ejercicio de cómo se les asıgnan nuevos significados culturales a los elementos apropıados, que formulan explicaciones introspectivas sobre dichas contingencias

Asıgnar un nuevo significado cultural no es un fenómeno que opere en exclusiva frente al contexto del contacto interetnico o para explicar la intervención de los occidentales en las sociedades indigenas A cada transformación cultural corresponde una re elaboración del sıgnificado que explıque como por que o para que sirve dicha transformacion De alguna forma, y ya que esto es unherente a las relaciones de poder y del ejercicio de la politıca, lo que esta en juego son la veracidad y la actualidad del significado dentro de estas ielaciones (Wolf, 2003 337-338) Si el poder es intrinseco a la significación en las relaciones politicas ( sean estas de contacto unteretnico o no), entonces 
Los pueblos indıos y la sociedad mayor niveles de integracion y formas de dominı la resıgnificacion es inherente a las transformaciones y las mudanzas culturales, pues es la forma de dar sentıdo y revitalızar las categorías en defensa de su veracıdad

La adquisición de nuevos elementos, sean tierras, empleos o servicios es una consecuencia mas del contacto interetnico de las relaciones de poder entıe la sociedad dominante y la sociedad indı gena que orıgina la activacion de estrategıas que formulen explıca ciones sobre las transformaciones culturales A traves de un pioceso de ocupacion del espacio que no corresponde a lo que es considerado tradicional" se crea una serıe de practicas culturales que intentan fundamentar dentro de las prescripciones culturales pero que frente a las condiciones actuales dificilmente se apegan a estas Ası, las practicas culturales de los indıos tienen que ser explicadas por ellos mismos, en la creación de dıscursos en doble sentıdo, surgıdos a partır de los propios codigos nativos y utılızando elementos de la sociedad envolvente que son estrategicamente apropiados

\section{Bibliografía}

AGUILAR ROBLEDO Miguel Haciendas y condueñazgos en la Huaste ca potosina notas introductorias In RUVALCABA MERCADO Jesus (Coord) Nuevos aportes al conocimiento de la Huasteca Mexico DF CIE SAS CIHSLP CEMCA IPN UACh INI I998 p 123 I52

BOTT Rosa Maria Levantamento etnografico de um grupo Guarant Florianopo lis Museu de Antropologia e Etnologia Brasıleira, 1975

CARRERA QUEZADA Sergı Eduardo A terra de Nhanderu organızação so ciopolıtıca e processos de ocupação teırıtorıal dos Mbya-Guaranı em San ta Catarına Dissertação (Mestıado em Antropologıa Socıal) - Centro de Fılosofıa e Ciências Humanas, Unıversıdade Federal de Santa Catarına Florianopolıs 2007

CARRERA QUEZADA Sergio Eduardo A son de campana la fragua de Xo chiatipan Mexico DF CIESAS UAH COLSAN 2008 (Coleccion Huas teca)

CHASE SARDI Miguel El precto de la sangre Tuguy ñe e repy estudıo de la cultura y control social entıe los Ava Guaranı Asuncion Centro de Estu dios Antropologicos 1992 (Biblioteca Paiaguaya de Antıopologia 16)

CICCARONES Celeste Drama e sensibiltdade migração xamanısmo e mu lheres Mbya Guaranı Tese (Doutorado em Ciências Sociass) - Pontıficia Unıversıdade Catolıca de São Paulo São Paulo 2001 
CRUZ PERALTA Clemente Los bienes de los santos cofradias y hermandades de la Huasteca en la epoca colonial 2009 No pielo

CHIPMAN Donald E Nuno de Guzman and the Province of Panuco in New Spain 15181533 Mexico DF CIESAS COLSAN UAT 1967 (Coleccion Huaste ca) The Arthur H Clark Company Glendale (Spain in the West X) Tra ducido al español como Nuño de Guzman y la provincia de Panuco en Nueva España 15181533

DARELLA Maria Dorothea Post Ore Rotpota Yvy Porã Nos Queremos Terra Boa territorıalızação guaran no litoral de Santa Catarma Brasıl Tese (Doutorado em Ciências Sociaıs) - Pontıfıcıa Unıversıdade Catolıca de São Paulo São Paulo 2004

DARELLA Marıa Dorothea Post GARLET Ivorı J ASSIS Valeria Estudo de impacto as populações indıgenas e a duplıcação da BR 10I trecho Palho ça/SC Osorı/RS Floıınopolıs São Leopoldo 2000 Relatorıo requerıdo pelo Departamento Nacional de Infra Estrutura de Transportes

GARLET Ivorı J Mobılıdade mbya histona e sıgnificação Dissertação (Mes trado em Historia Iberoamericana) - Pontıficia Universidade Catolica do Rio Grande do Sul Porto Alegre 1997

ICIEK Aleksandra Estructuras comunitarias de la congregacion de Hueyuatitla frente a los cambios socioeconomicos contemporaneos Universidad de Varsovia 2009 No prelo

LADEIRA Mana Inês Aldelas guaranı do litoral de Santa Catarina São Paulo 1991 Relatono CTI

LADEIRA Marıa Inês O caminhar sob a luz o territorıo mbya a beira do ocea no Dissertação (Mestıado em Ciêncıas Socıaıs) - Pontufıcıa Unıversıdade Catolıca de São Paulo São Paulo 1992

LADEIRA Marıa Inês Terra indigena Morro dos Cavalos Tekoa Yma São Pau lo 2002 Relatorıo de ldentufıcação e Delumıtação Relatorıo requerıdo pela FUNAI

LITAIFF Aldo As divinas palavras ıdentıdade etnica dos Guaranı Mbya Flo rianopolss Ed da UFSC 1996

LITAIFF Aldo Relatorio de eleıção da area a ser destınada pela TBG aos indios Mbya Guarant do litoral do Estado de Santa Catarna Flonanopolıs 1999 Relatorıo requerıdo pela Empresa Transportadora Brasıleira Gasoduto Bolıvia Bra sil

MELIA Bartolomeu Pueblos indigenas en el Paraguay demografia historica y analısis de los resultados del Censo Nacional de Poblacion y Viviendas 1992 Asuncion Presidencia de la Republica Fondo de las Naciones Unı das para Actıvidades de Poblacion 1997

MELIA Bartolomeu GRUNBERG Georg GRUNBERG Fnedl Etnografia guaranı del Paraguay contemporaneo los Paĩ Tavyterã Suplemento Antro pologico Universidad Catolica Nuestra Señora de la Asuncion Asuncion v $11 \mathrm{n} 12 \mathrm{p} 1512951976$

MELlO Flavia Cristina de Aata Tape Rupy segundo pela estrada uma in vestıgação dos deslocamentos territorıaıs realızados por familıas mbya- 
guaranı no Sul do Brasıl Dıssertação (Mestrado em Antropologıa Social) - Centro de Filosofia e Ciêncıas Humanas, Unıversıdade Federal de Santa Catarina Flonanopolis 2001

NOELLI Francisco Sem tekoha não ha teko em busca de um modelo etnoar queologıco da aldeıa e da subsıstêncıa guaranı e sua aplıcação a uma área de domınıo no delta do Rıo Jacuı RS Dıssertação (Mestrado em Historıa Iberoamerıcana) - Pontıfıcıa Unıversıdade Catolıca do Rıo Grande do Sul Porto Alegre 1993 3v

NOELLI Francısco A ocupação humana na regıão Sul do Brasıl arqueolo gia debates e perspectivas 18722000 Revista USP São Paulo n 44 p 21826919992000

NOELLI Francisco Distribucion geografica de las evidencias arqueologicas Guaranı Revista de Indias Madrid n 64 p 17342004

PEREZ ZEVALLOS Juan Manuel La Huasteca en el siglo XVI fragmentacion de los señorios prehıspanıcos organızacion social y tributo Tese (Licen clatura em Ciencias Antropologicas) - Escuela Nacional de Antropologia e Histona Mexico 1983

PEREZ ZEVALLOS Juan Manuel Visita de Gomez Nieto a la Huasteca (1532 1533) paleografia introduccion y notas de Mexico DF CIESAS ColSan CEMCA AGN 2001 (Coleccion Huasteca)

PERRONE MOISES Leyla Vinte luas viagem de Paulmier de Gonneville ao Brasil 15031505 São Paulo Companhia das Letras 1996

PISSOLATO Elizabeth de Paula A duração da pessoa mobilıdade parentesco e xamanısmo mbya (guaranı) Tese (Doutorado em Antiopologia Social) - Universidade Federal do Rio de Janeuro Rio de Janeiro 2006

RUVALCABA MERCADO Jesus Exploitation discrimination et violen ce dans la Huasteca indienne In LAMMEL Annamaria RUVALCABA MERCADO Jesus (Ed) Adaptation violence et revolte au Mexique Paris L Harmattan 2002 p 223246 (Recheiches Ameriques Latines)

RUVALCABA MERCADO Jesus Fstado y violencia en el medıo rural de Me xico y Brasil Desacatos Revista de Antropologia Social Mexico DF CIESAS n 14 p 1691862004 (Juventud Exclusion y Violencia)

SANTIAGO Myrna De paraiso a tierrabaldia ambiente yextraccion pe trolera en la Huasteca veracruzana 19081921 In OHMSTEDE Antonı Escobar LAMADRID Luz Carregha (Coord) El siglo XIX en las Huastecas Mexico DF CIESAS El Colegio de San Luis 2002 (Coleccion Huasteca)

SANTOS SANTOS Pedro Antonio Historia antigua de los tres partidos de la Huasteca potosina memorias de un criollo San Luis Potosi Archivo Histo rico del Estado de San Luis Potosı 1991

SANTOS Silvio Coelho dos Educação e soctedades tribats Porto Alegre Movı mento 1975

SANTOS Silvio Coelho dos (Coord) Parque Estadual do Tabuletro aspectos culturais e sociaıs Flollanopolıs UFSC FATMA 1976 v I 
SANTOS Sílvio Coelho dos Indıos e brancos no Sul do Brastl a dramatıca expe riência dos Xokleng Porto Alegre Movimento 1987

SANTOS Silvio Coelho dos Povos indigenas e a Constztunte Porto Alegre Mo vimento Florlanopolis Ed da UFSC 1989

SANTOS Silvio Coelho dos Presas y cuestiones socio ambientales en el Bra sil Alteridades, Iztapalapa UAM v 2 n 4 p 31371992 (Reacomodos y construccion de presas)

SANTOS Silvio Coelho dos Constitucion y violacion de los derechos de los pueblos indigenas en el Brasil In GRUNBERG Georg (Coord) Artıcula cion de la diversidad tercera reunion de Barbados Quito Abya Yala 1994 p 161174 (Biblioteca Abya Yala 27)

SANTOS Silvio Coelho dos A geração hidnica de eletricidade no Sul do Bra sil e seus impactos sociais Etnogafica Lisboa v 7 n I p 871032003

SANTOS Sulvio Coelho dos Noticia sobie os Carijo In SANTOS Silvio Coe lho dos NACKE Aneliese REIS, Maria Jose (Org) São Francisco do Sul muito alem da viagem de Gonneville Florianopolıs Ed da UFSC 2004 p 4047

SANTOS Silvio Coelho dos Indıos direitos e violência oficıal In DIALO GOS TRANSVERSAIS EM ANTROPOLOGIA 2006 UFSC, Flonanopolis Anats Florianopolis 2006

SANTOS Silvio Coelho dos Ensaios oportunos Florianopolıs Academia Cata rinense de Letras Nova Letra 2007 (Coleção ACL 29)

STRESSER PEAN Guy San Antono Nogalar la Sierra de Tamaulipas y la frontera noreste de Mesoamerica Mexico DF Centro de Investıgaciones y Estudios Superiores en Antropologia Social Unıversidad Autonoma de Tamaulıpas Centro Frances de Estudios Mexicanos y Centroamenicanos El Colegio de San Luis 2000 (Coleccion Huasteca)

SUSNIK Branıslava El indio colonial del Paraguay el Guaranı colonial Asun cion Museo Etnografico Andres Barbero 1965 v 1

WILKERSON S Jeffrey $\mathrm{K}$ Man s Eighty Centuries in Veracruz The National Geographic Magazıne, Washungton, v 158 n 2, p 202231 Aug 1980

WOLF, Enc R Encarando o poder velhos insights novas questões In FELDMAN BIANCO Bela RIBEIRO Gustavo Lins (Org) Antropologia e poder contribuições de Erıc R Wolf Brasilıa Ed da UnB Imprensa Oficial Unicamp 2003

ZARAGOZA OCAÑA Diana Intercambios comerciales prehıspanicos entre el area de Guadalcazar y la Huasteca In RUVALCABA MERCADO Jesus (Coord) Nuevos aportes al conocimiento de la Huasteca Mexico DF CIESAS CIHSLP CEMCA IPN UACh INI 1998 p 3138 